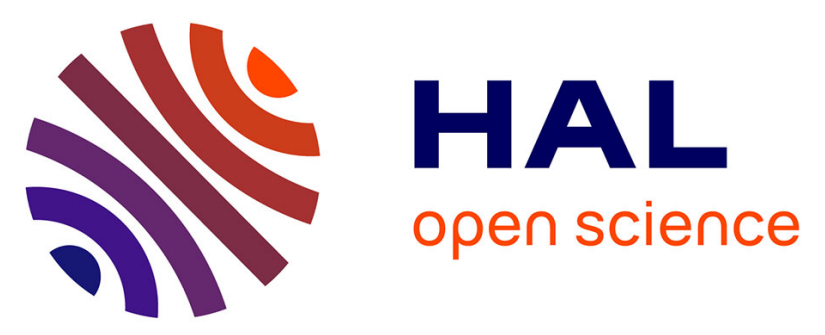

\title{
Investigation of crystallization mechanisms for polymorphic and habit control from the Supercritical AntiSolvent process
}

Sébastien Clercq, Adil Mouahid, Pèpe Gérard, Elisabeth Badens

\section{- To cite this version:}

Sébastien Clercq, Adil Mouahid, Pèpe Gérard, Elisabeth Badens. Investigation of crystallization mechanisms for polymorphic and habit control from the Supercritical AntiSolvent process. Journal of Supercritical Fluids, 2018, 141, pp.29-38. 10.1016/j.supflu.2017.11.025 . hal-02113962

\section{HAL Id: hal-02113962 \\ https://hal-amu.archives-ouvertes.fr/hal-02113962}

Submitted on 29 Apr 2019

HAL is a multi-disciplinary open access archive for the deposit and dissemination of scientific research documents, whether they are published or not. The documents may come from teaching and research institutions in France or abroad, or from public or private research centers.
L'archive ouverte pluridisciplinaire HAL, est destinée au dépôt et à la diffusion de documents scientifiques de niveau recherche, publiés ou non, émanant des établissements d'enseignement et de recherche français ou étrangers, des laboratoires publics ou privés. 


\title{
Investigation of crystallization mechanisms for polymorphic and habit control from the Supercritical AntiSolvent process
}

\author{
Sébastien Clercq, ${ }^{\mathrm{a}, *}$, Adil Mouahid ${ }^{\mathrm{a}}$, Pèpe Gérard ${ }^{\mathrm{b}}$, Elisabeth Badens ${ }^{\mathrm{a}}$
}

a Aix Marseille Univ, CNRS, Centrale Marseille, M2P2 UMR 7340, 13451, Marseille, France

${ }^{\mathrm{b}}$ Aix Marseille Univ, CNRS, CINaM UMR 7325, 13288, Marseille, France

\section{G R A P H I C A L A B S T R A C T}

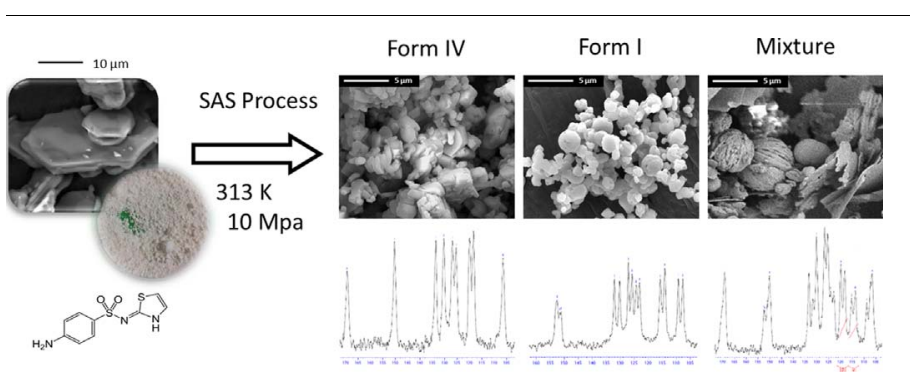

\section{A R T I C L E I N F O}

\section{Keywords:}

Supercritical $\mathrm{CO}_{2}$

Sulfathiazole

Crystallization

Supercritical AntiSolvent

Polymorphism

Habit

\begin{abstract}
A B S T R A C T
In this work, the Supercritical AntiSolvent (SAS) process has been used to generate micronized crystals of Sulfathiazole (STZ) from different organic solutions, namely acetone, acetonitrile, tetrahydrofuran and acetic acid. The flow rates of $\mathrm{CO}_{2}\left(2-21 \mathrm{~g} \mathrm{~min}^{-1}\right)$ and of the organic solution $\left(0.19-6 \mathrm{~mL} \mathrm{~min}{ }^{-1}\right)$, as well as STZ concentration in the organic solution (20-70\% under the saturation), have been varied to identify the conditions leading to powders exhibiting only one polymorphic form. Pressure (10 MPa) and temperature (313 K) have been kept constant. In this paper, thermodynamic and hydrodynamic aspects are discussed so as to rationalize the obtained crystal characteristics and provide a new way to control the SAS process applied to drug preformulation. The influence of the organic solvent nature on both the polymorphic form and the habit of generated crystals, has been particularly discussed.
\end{abstract}

\section{Introduction}

Crystallization processes involving a supercritical medium are gaining momentum as they are regarded as environmentally friendly processes and allow good control over product properties, especially particle size, Particle Size Distribution (PSD), crystal habit and polymorphic form. This is mainly because crystallization processes using sc$\mathrm{CO}_{2}$ often involve only one crystallization step, unlike conventional methods of crystallization in solution. $\mathrm{CO}_{2}$ being gaseous at ambient conditions of pressure and temperature, the separation of $\mathrm{CO}_{2}$ from the end-products is spontaneous and does not require successive separation operations. Thus, a single-step process or a process involving a reduced number of steps will lead to the formation of powders with homogeneous characteristics. When a series of steps is involved, the size as well as the habit or the polymorphic nature of the crystals may evolve. The good control of powder characteristics using supercritical fluids is also due to the large number of operating parameters and conditions (pressure, temperature, hydrodynamics and mixing conditions, supersaturation level, etc.) that can extensively be varied, therefore allowing efficient screenings for particle drug design. Amongst the different

\footnotetext{
* Corresponding author.

E-mail address: sebastien.clercq@univ-amu.fr (S. Clercq).
} 
supercritical processes, the Supercritical AntiSolvent (SAS) process, using supercritical carbon dioxide $\left(\mathrm{sc}-\mathrm{CO}_{2}\right)$ as crystallization antisolvent, brings particular interest for drug reprocessing [1-9], that are often sparingly soluble into sc- $\mathrm{CO}_{2}$.

Crystallization during the SAS process is both induced by the sc- $\mathrm{CO}_{2}$ antisolvent effect and by the organic solvent depletion. When the organic solution containing the solute to recrystallize and sc- $\mathrm{CO}_{2}$ are put in contact, the organic solvent diffuses into the $\mathrm{CO}_{2}$-rich phase while $\mathrm{CO}_{2}$ diffuses into the organic solution-rich phase, quickly leading to solute supersaturation in the organic solution's expanded phase. Crystal size is often at the micron or sub-micron order of magnitude thanks to the rapid transfer phenomena in supercritical media, which represents one of the most important assets of this technology.

This paper presents an experimental application of drug reprocessing by SAS, using Sulfathiazole (STZ) as the solute to be recrystallized. This compound, a veterinary drug, has a complex drug behavior regarding its ability to crystallize into five known polymorphic forms [10]. For that criterion, it has been widely described in literature either for crystallographic investigations [11-15] or for crystallization behavior into both liquid phases $[16,17]$ or supercritical media [18-20]. It is worth noting that different nomenclatures exist for the five polymorphic forms of Sulfathiazole. In this study, the nomenclature proposed by Apperley et al. has been adopted [13]. A brief description of the five crystal cells and their Cambridge Structural Database (CSD) reference are given in Table 1.

Two forms are commonly observed throughout experimentations, namely so-called forms I and IV. At ambient conditions, the relative stability is IV > I. Furthermore, Munroe et al. [21] investigated the relative stabilities of the five polymorphs of Sulfathiazole depending on the temperature. It appears that, from $283 \mathrm{~K}$ up to $323 \mathrm{~K}$ at atmospheric pressure, polymorphic form I is the least stable of all five forms, then this order follows: I $<$ II $<$ V $<$ IV $<$ III.

Commonly, process development around drug particle generation consists in optimizing the drug bioavailability by reducing its size, narrowing its size distribution and controlling both crystal habit and polymorphism. As mentioned above, the SAS process can be tuned to target given specific properties of the end-product. Temperature, pressure, solute concentration in the feeding solution and flow rates of both $\mathrm{CO}_{2}$ and organic solution phases are commonly screened parameters [22]. Erriguible et al. [23] proposed a complete 3D simulation of the SAS process by varying operating conditions in a range of typical target conditions. They have investigated the crystallization of a solution of minococycline-ethanol and predicted a reduction of particle size by decreasing the solid-fluid interfacial tension as well as by increasing the initial concentration in the feeding solution or by increasing the injection jet velocity. Estimation of the interfacial tension has been reported as of major interest to consider the simulation as a predictive tool. Jet dispersion conditions of the organic solution were reported as a significant criterion to control particle characteristics by Petit-Gas et al. [24]. They have studied the crystallization of a solution of STZ-acetone in $\mathrm{SC}-\mathrm{CO}_{2}$. Finer particles of STZ were obtained for higher jet velocities, but also with larger capillary internal diameter at a constant jet velocity. Furthermore, different morphologies were observed, corresponding to different polymorphic forms of STZ crystals, for different Reynolds number values of the organic solution. Careno et al. [25] and
Boutin et al. [26] studied alternative injection technology, namely impinging jets and concentric tubes, to greatly enhance phase mixing and mass transfers, thus reducing crystal size, for STZ-acetone and STZmethanol systems. Other enhanced mass transfer conditions were successfully achieved for the SAS process, by atomizing the liquid jet on a vibrating surface at an ultrasonic frequency [27] (Griseofulvin-dichloromethane and Griseofulvin-tetrahydrofuran systems) or by stirring [28] (Griseofulvin-acetone system). As for conventional recrystallization methods in solution, the organic solvent nature has also been reported as one of the most significant factors that control the SAS process and crystal habit. It has been proven that changing the organic solvent $[29,30]$, or adding a growth inhibitor [31], may modify the crystal habit without modifying its crystal structure. A probable explanation is that the growth of one crystal's face may be selectively slowed down in comparison to the others due to solvent-or growth inhibitor-adsorption, which depends on the interaction between the solvent molecules and the solute molecules on crystal faces.

However, predicting and controlling the polymorphic form of the solute crystals has been less extensively studied. Kordikowski et al. [32] showed in the case of STZ recrystallized from acetone, that the flow ratio $\left(\mathrm{CO}_{2}\right.$ /acetone) has a preponderant role influencing the polymorphic form, whilst temperature has a preponderant role in the case of STZ reprocessed from methanol. The polymorphic form of STZ has therefore been related to the choice of solvent. Bouchard et al. [33] highlighted a strong dependence of glycine polymorphic form behavior on both the solute concentration into the feed and the ethanol fraction in the $\mathrm{CO}_{2}$-rich phase. The form IV is obtained for higher solute concentration and lower ethanol fraction, thus for higher supersaturation values. Later, Rossmann et al. [34] investigated the case of paracetamol, concluding that varying the solvent nature, in this case acetone, ethanol and a mixture of both, can lead to a modification of the crystalline form.

In this work, SAS process experiments were carried out at constant temperature $(313 \mathrm{~K})$ and pressure $(10 \mathrm{MPa})$, but organic solution and sc- $\mathrm{CO}_{2}$ flow rates, STZ concentration and organic solvent nature were varied with the aim of obtaining powders exhibiting only one polymorphic form. Thirteen solvents exhibiting different polarity and proticity properties were tested in a preliminary solubility measurement study at ambient pressure. Among them, four were retained for the SAS experiments according to their solvent power regarding STZ: acetone, acetonitrile, tetrahydrofuran and acetic acid. Solubility measurements of STZ in the four selected organic solvents were performed to evaluate the saturation degree of the initial organic solution used for the SAS process. The powders were characterized by ${ }^{13} \mathrm{C}$ Nuclear Magnetic Resonance (NMR) to determine the nature of the polymorphic forms obtained pure or in mixture. Pure crystalline powders in terms of polymorphic form were also observed by Scanning Electron Microscopy (SEM). Crystal characteristics were then discussed by considering the varied operating conditions corresponding to different thermodynamic and kinetic conditions.

\section{Materials and methods}

\subsection{Materials}

STZ (polymorphic form III), acetone and tetrahydrofuran were

Table 1

Crystal lattice for the five polymorphic forms of Sulfathiazole.

\begin{tabular}{|c|c|c|c|c|c|}
\hline Polymorphic form & I & II & III & IV & $\mathrm{V}$ \\
\hline CSD Ref. Code & SUTHAZ01 & SUTHAZ05 & SUTHAZ02 & SUTHAZ & SUTHAZ04 \\
\hline a $(\AA)$ & 10.554 & 10.399 & 17.570 & 8.235 & 10.867 \\
\hline $\mathrm{b}(\AA)$ & 13.220 & 15.132 & 8.570 & 8.550 & 8.543 \\
\hline c $(\AA)$ & 17.050 & 14.280 & 15.583 & 15.580 & 11.456 \\
\hline$\beta(\mathrm{deg})$ & 108.06 & 91.21 & 112.93 & 93.67 & 88.13 \\
\hline
\end{tabular}




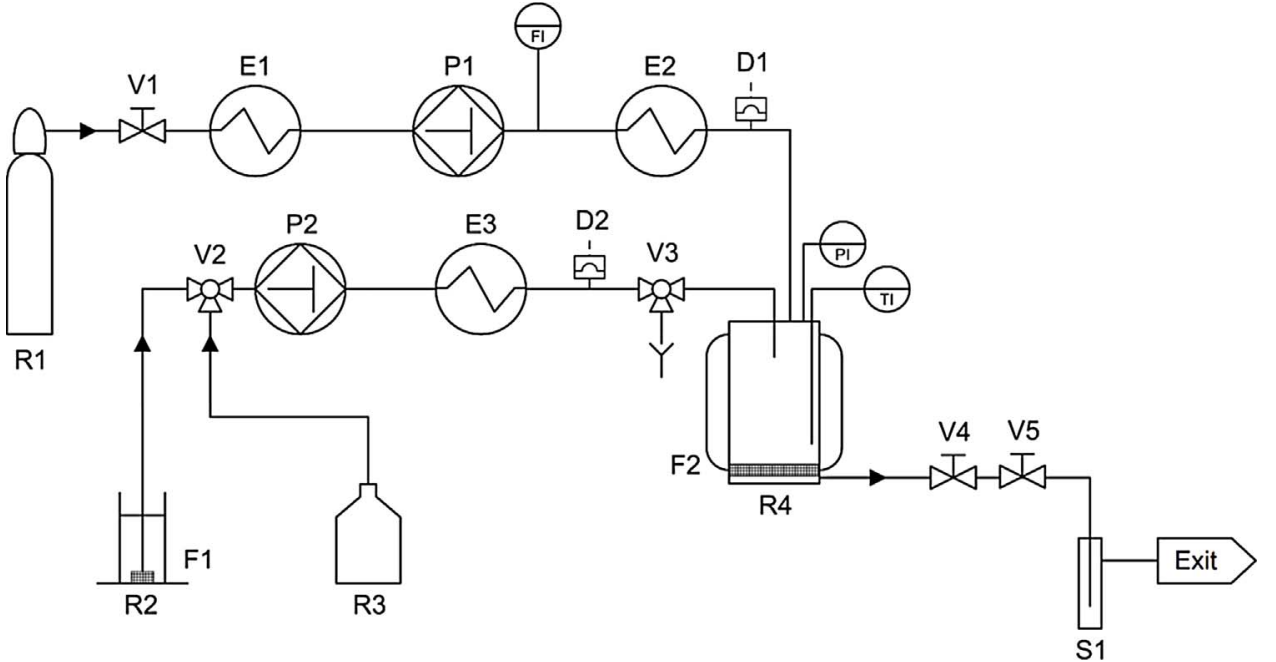

Table 2

List of solvents used for the solubility measurements at ambient pressure. $\mathrm{PA}=$ polar aprotic; $\mathrm{PP}=$ polar protic; $\mathrm{NP}=$ non-polar.

\begin{tabular}{llllll}
\hline Solvent & Origin & \#CAS & $\varepsilon[35]$ & Nature & $\begin{array}{l}C_{s} \text { at } 313 \mathrm{~K} \\
(\% \mathrm{w} / \mathrm{w})\end{array}$ \\
\hline Ethanol & $\begin{array}{l}\text { Sigma- } \\
\text { Aldrich }\end{array}$ & $64-17-5$ & 25.30 & $\mathrm{PP}$ & $\approx 0.75$ \\
& Carlo-Erba & $71-23-8$ & 20.80 & & $<0.75$ \\
Propanol-1 & Carlo-Erba & $67-63-0$ & 20.18 & $<0.75$ \\
Propanol-2 & Fisher & $64-19-7$ & 6.20 & 0.83 \\
Acetic acid & SDS & $67-68-5$ & 47.24 & PA & $>10$ \\
Dimethyl sulfoxide & VWR & $75-05-8$ & 36.64 & & 1.42 \\
Acetonitrile & Sigma- & $872-50-$ & 32.55 & & $>10$ \\
N-Methyl-2- & Aldrich & & & & 3.11 \\
$\quad$ pyrrolidone & Sigma- & $67-64-1$ & 21.01 & & 1.15 \\
Acetone & Aldrich & & & & $<0.75$ \\
& Sigma- & $109-99-9$ & 7.52 & & $<0.75$ \\
Tetrahydrofuran & Aldrich & & & & $<0.75$ \\
Ethyl acetate & Carlo-Erba & $141-78-6$ & 6.08 & & $<0.75$ \\
Chloroform & Carlo-Erba & $67-66-3$ & 4.81 & NP & \\
Diethyl ether & SDS & $60-29-7$ & 4.27 & & \\
Limonene & Prolabo & $138-86-3$ & 2.37 & & \\
\hline
\end{tabular}

purchased from Sigma-Aldrich, France; Acetonitrile was purchased from VWR; Acetic acid was purchased from Fisher, France. All chemicals were purchased at purity $>98 \%$ and were used without further purifications. Carbon dioxide (purity of 99.7\%) was purchased from Air Liquide, France.

\subsection{Solubility measurements procedure}

STZ and organic solvent are mixed together with a magnetic stir bar in a sealed container with an intentional excess of solute. The container is placed in a temperature bath regulated at $313 \mathrm{~K}$. After several hours, the agitation is stopped and a part of the supernatant is collected with a syringe equipped by a millipore filter (VWR $-0.45 \mu \mathrm{m}$ ). This sample is immediately diluted in a weighed quantity of pure solvent to prevent the crystallization from occurring through cooling. The concentration of the diluted solution is given by density measurement, referred to a calibration curve, with a density meter DMA $5000 \mathrm{M}$ Anton (precision of $10^{-6} \mathrm{~g} \mathrm{~cm}^{-3}$ ), at $293 \mathrm{~K}$.

\subsection{Experimental set-up for SAS process}

The experimental apparatus used for this study is detailed in Fig. 1. It includes a $480 \mathrm{~mL}$ (internal diameter: $60 \mathrm{~mm}$ ) double jacket autoclave (TOP INDUSTRIE, France). The maximum allowable pressure is
Fig. 1. Apparatus for crystallization using the SAS process. E1 to E3: heat exchangers; V1: valve; V2 and V3: 3-ways valves; V4 and V5: depressurizing valves; P1 and P2: high pressure liquid piston pumps; D1 and D2: rupture discs, F1: solvent frit filter; F2: glass fiber filter; S1: cold solvent trap; R1: $\mathrm{CO} 2$ pressurized bottle; R2: organic solution tank; R3: pure solvent tank; R4: crystallization autoclave.
$25 \mathrm{MPa}$ at a temperature of $423 \mathrm{~K}$. It is equipped with pressure and temperature sensors, as well as an $18 \mathrm{MPa}$ rupture disk. The fluids, namely $\mathrm{CO}_{2}$ and organic solution, are injected at the top of the autoclave thanks to two high pressure liquid piston pumps (SEPAREX, France and GILSON, France, respectively for $\mathrm{CO}_{2}$ and organic solution). Organic solution feed is injected through a $127 \mu \mathrm{m}$ internal diameter capillary tube. $\mathrm{CO}_{2}$ flow is measured thanks to a Coriolis Effect flowmeter (BRONKHORST, France). A frit filter $(2 \mu \mathrm{m})$ and a glass fiber filter $(1.2 \mu \mathrm{m})$ are placed at the bottom of the autoclave to retain and easily collect generated particles. A cold solvent trap allows the separation of exiting fluids: $\mathrm{CO}_{2}$ is evacuated and organic solution is recycled.

\subsection{Experimental procedure}

A first step consists in stabilizing the composition in the autoclave at the target conditions by injecting $\mathrm{CO}_{2}$ and pure solvent. The target pressure and target temperature have been respectively fixed at $10 \mathrm{MPa}$ and $313 \mathrm{~K}$ to ensure monophasic conditions. When the target conditions are reached, exit valves are open and the operating conditions are stabilized. Then, pure solvent feed is replaced by the organic solution, containing the solute to be crystallized. The solute concentration is given as a fraction of the organic solution saturation at $313 \mathrm{~K}$, noted ßos.

From that time on, sc- $\mathrm{CO}_{2}$ has an antisolvent role. $\mathrm{CO}_{2}$ and organic solvent reversediffusion occurs due to concentration gradient, causing a rapid and large supersaturation, thus a fast crystallization.

The generated particles are retained at the bottom of the autoclave. At the end of the injection step, the injection line is washed with pure solvent to avoid nozzle clogging, then the organic solvent flow is stopped. The $\mathrm{CO}_{2}$ flow is kept so as to renew the fluid phase content in the autoclave and dry the crystalline powder, from 3 up to 5 residence time. At the end of these washing steps, the autoclave pressure is dropped to atmospheric pressure and the powder that has been accumulated on the filter is collected.

The experimental conditions tested in this work are listed in Table 3 (see part 3.2). Feed flows of both phases as well as STZ concentration into the organic solution were varied to identify which operating conditions allow the formation of pure powders in term of polymorphic form, for each studied solvent, namely acetone (Acet), acetonitrile (ACN), tetrahydrofuran (THF) and acetic acid (AcAc). $\mathrm{CO}_{2}$ and organic solution flow rates were varied from 2 up to $21 \mathrm{gmin}^{-1}$ and from 0.19 up to $6 \mathrm{~mL} \mathrm{~min}^{-1}$ respectively. Thus, solvent to $\mathrm{CO}_{2}$ molar ratios $\left(\mathrm{X}_{\text {solv }}\right.$ $\mathrm{CO} 2$ ) were varied from 5 up to $23 \mathrm{~mol} \%$. 
Table 3

Experimental conditions. Acet $=$ Acetone, $\mathrm{ACN}=$ acetonitrile, $\mathrm{THF}=$ tetrahydrofuran, $\mathrm{AcAc}=$ acetic acid.

\begin{tabular}{|c|c|c|c|c|c|c|c|c|}
\hline \# Exp. & Solvent & OS flow rate $\left(\mathrm{mL} \mathrm{min}^{-1}\right)$ & $\mathrm{CO}_{2}$ flow rate $\left(\mathrm{g} \mathrm{min}^{-1}\right)$ & $\mathrm{Re}_{\mathrm{jet}}$ & $\operatorname{Re}_{\mathrm{CO} 2}$ & $\beta_{\mathrm{OS}}(\%)$ & $\mathrm{X}_{\mathrm{solv} / \mathrm{CO} 2}(\mathrm{~mol} \%)$ & Polymorph \\
\hline 1 & \multirow[t]{12}{*}{ Acet } & 4 & 21 & 1529 & 155 & \multirow[t]{4}{*}{60} & 11 & Mixture (I + IV) \\
\hline 2 & & 3.5 & 21 & 1338 & 155 & & 9.6 & Mixture (I + IV) \\
\hline 3 & & 3 & 21 & 1147 & 155 & & 8.2 & I \\
\hline 4 & & 1.9 & 21 & 726 & 155 & & 5.2 & Mixture (I + IV) \\
\hline 5 & & 1.9 & 21 & 726 & 155 & 40 & 5.3 & Mixture (I + IV) \\
\hline 6 & & 1.9 & 21 & 726 & 155 & 20 & 5.3 & Mixture (I + IV) \\
\hline 7 & & 1.9 & 10 & 726 & 74 & \multirow[t]{6}{*}{60} & 11 & IV \\
\hline 8 & & 1.9 & 5 & 726 & 37 & & 22 & Mixture (I + IV) \\
\hline 9 & & 1.38 & 15 & 528 & 111 & & 5.3 & Mixture (I + IV) \\
\hline 10 & & 0.91 & 10 & 348 & 74 & & 5.3 & Mixture (I + IV) \\
\hline 11 & & 0.42 & 5 & 161 & 37 & & 4.8 & IV \\
\hline 12 & & 0.19 & 2 & 73 & 15 & & 5.5 & IV \\
\hline 13 & \multirow[t]{15}{*}{ ACN } & 6 & 21 & 2157 & 155 & \multirow[t]{2}{*}{60} & 23 & Mixture (I + IV) \\
\hline 14 & & 5 & 21 & 1797 & 155 & & 19 & Mixture (I + IV) \\
\hline 15 & & 3 & 21 & 1078 & 155 & 70 & 11 & Mixture (I + IV) \\
\hline 16 & & 2.5 & 10 & 899 & 74 & \multirow[t]{2}{*}{60} & 20 & Mixture (I + IV) \\
\hline 17 & & 2 & 8 & 719 & 59 & & 20 & Mixture (I + IV) \\
\hline 18 & & 1.9 & 21 & 683 & 155 & 70 & 7.3 & I \\
\hline 19 & & 1.9 & 21 & 683 & 155 & \multirow[t]{3}{*}{60} & 7.3 & IV \\
\hline 20 & & 1.9 & 10 & 683 & 74 & & 15 & Mixture (I + IV) \\
\hline 21 & & 1.5 & 8 & 539 & 59 & & 15 & Mixture (I + IV) \\
\hline 22 & & 1.35 & 21 & 485 & 155 & 70 & 5.2 & IV \\
\hline 23 & & 1.35 & 21 & 485 & 155 & \multirow[t]{5}{*}{60} & 5.2 & IV \\
\hline 24 & & 1.25 & 5 & 449 & 37 & & 20 & Mixture (I + IV) \\
\hline 25 & & 1 & 8 & 359 & 59 & & 10 & Mixture (I + IV) \\
\hline 26 & & 0.94 & 5 & 338 & 37 & & 15 & Mixture (I + IV) \\
\hline 27 & & 0.63 & 5 & 226 & 37 & & 10 & Mixture (I + IV) \\
\hline 28 & \multirow[t]{13}{*}{ THF } & 6 & 21 & 2088 & 155 & \multirow[t]{13}{*}{60} & 15 & Mixture (III + IV) \\
\hline 29 & & 5 & 21 & 1797 & 155 & & 13 & Mixture (I + IV) \\
\hline 30 & & 3.8 & 10 & 1322 & 74 & & 20 & Mixture (III + IV) \\
\hline 31 & & 3.04 & 8 & 1058 & 59 & & 20 & I \\
\hline 32 & & 2.7 & 10 & 940 & 74 & & 14 & Mixture (I + IV) \\
\hline 33 & & 2.16 & 8 & 752 & 59 & & 14 & Mixture (I + IV) \\
\hline 34 & & 1.9 & 21 & 661 & 155 & & 4.8 & IV \\
\hline 35 & & 1.9 & 10 & 661 & 74 & & 10 & Mixture (I + IV) \\
\hline 36 & & 1.9 & 5 & 661 & 37 & & 20 & Mixture (I + IV) \\
\hline 37 & & 1.52 & 8 & 529 & 59 & & 10 & Mixture (I + IV) \\
\hline 38 & & 1.35 & 21 & 470 & 155 & & 3.4 & IV \\
\hline 39 & & 1.35 & 5 & 470 & 37 & & 14 & Mixture (I + IV) \\
\hline 40 & & 0.95 & 8 & 331 & 59 & & 10 & Mixture (I + IV) \\
\hline 41 & \multirow[t]{3}{*}{ AcAc } & 1.9 & 12 & 401 & 89 & \multirow[t]{3}{*}{60} & 12 & I \\
\hline 42 & & 1.17 & 15 & 247 & 111 & & 5.9 & I \\
\hline 43 & & 0.31 & 5 & 65 & 37 & & 4.7 & I \\
\hline
\end{tabular}

\subsection{Polymorphic form characterization using ${ }^{13} \mathrm{C} N M R$}

Each crystal powder was analyzed to determine the polymorphic form, or the composition of polymorph mixtures, of generated particles. $\mathrm{X}$-Ray Diffraction is a commonly encountered method, but can lack precision when it comes to quantitative analysis. In this work, solidstate Nuclear Magnetic Resonance was chosen for both the qualitative and quantitative analysis of STZ powders, using a BRUKER AVANCE III $400 \mathrm{MHz}$ spectrometer, working at a ${ }^{13} \mathrm{C}$ resonance frequency of $106 \mathrm{MHz}$. Characteristic NMR signals for STZ are taken from Apperley et al. [13].

\subsection{Particle observations by SEM}

Generated crystals are observed with a Scanning Electron Microscope to determine the crystal habit for each observed sample. Moreover, particle size and the size distributions was determined for the samples exhibiting only one polymorphic form. SEM observations were performed thanks to the JEOL JSM 6320-F device, working with a field emission gun. A metallization step with a gold plasma for $90 \mathrm{~s}$ was performed before each observation.

\section{Results and discussions}

\subsection{Solubility of sulfathiazole into organic solvent}

STZ solubility was measured into several solvents considered potentially eligible (either for toxicity or solubility in $\mathrm{SC}-\mathrm{CO}_{2}$ ) to be applied to the SAS process for recrystallizing active pharmaceutical ingredients. A list of every tested solvent is given in Table 2. They vary in their intrinsic properties of polarity and proticity and are classified according to their relative permittivity $\varepsilon$. Four solvents were selected, for which the solubility of STZ is included between 0.75 and $10 \%$ in weight concentration. Solubility lower than $0.75 \% \mathrm{w} / \mathrm{w}$. is quite low for a good productivity of the process whereas solubility higher than $10 \%$ w/w. may imply drug solubilization in the supercritical phase during the SAS process. These four solvents are acetone, acetonitrile, tetrahydrofuran and acetic acid. Every other tested solvent doesn't solubilize a large enough amount of STZ to be used in this study, except for dimethyl sulfoxide and N-Methyl-2-pyrrolidone, both solubilizing STZ over $10 \% \mathrm{w} / \mathrm{w}$. Logically, only polar solvents allow a good solubility for STZ, exhibiting a better affinity for aprotic solvents than for protic ones.

Solubility was obtained from calibration curves shown in Fig. 2, giving the density of the organic solution according to the concentration of STZ in it. Density measurements were performed at $293 \mathrm{~K}$. 

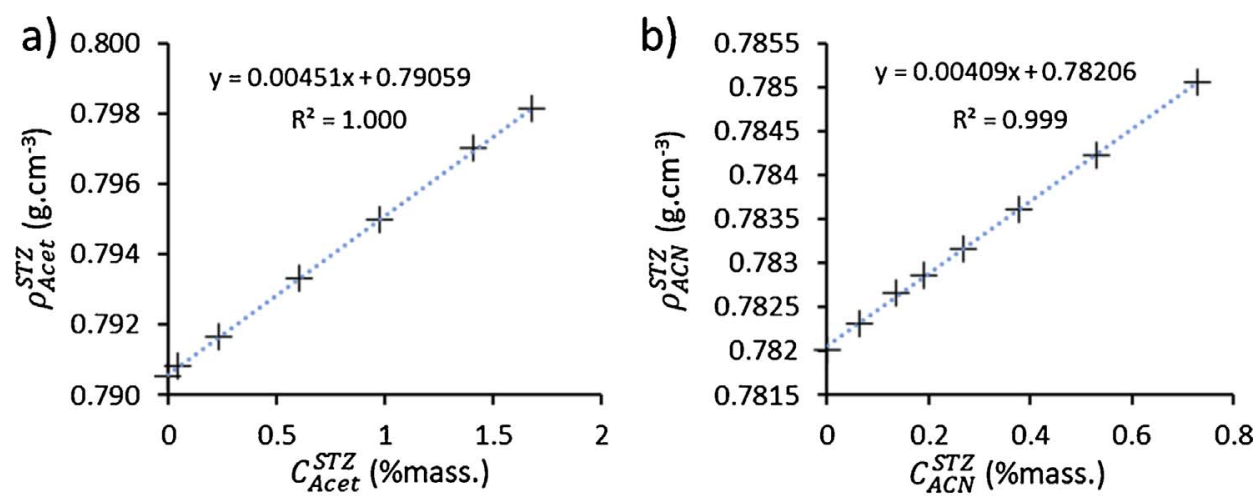

Fig. 2. Density calibration curves at $293 \mathrm{~K}$ for (a) acetone, (b) acetonitrile, (c) tetrahydrofuran, (d) acetic acid.
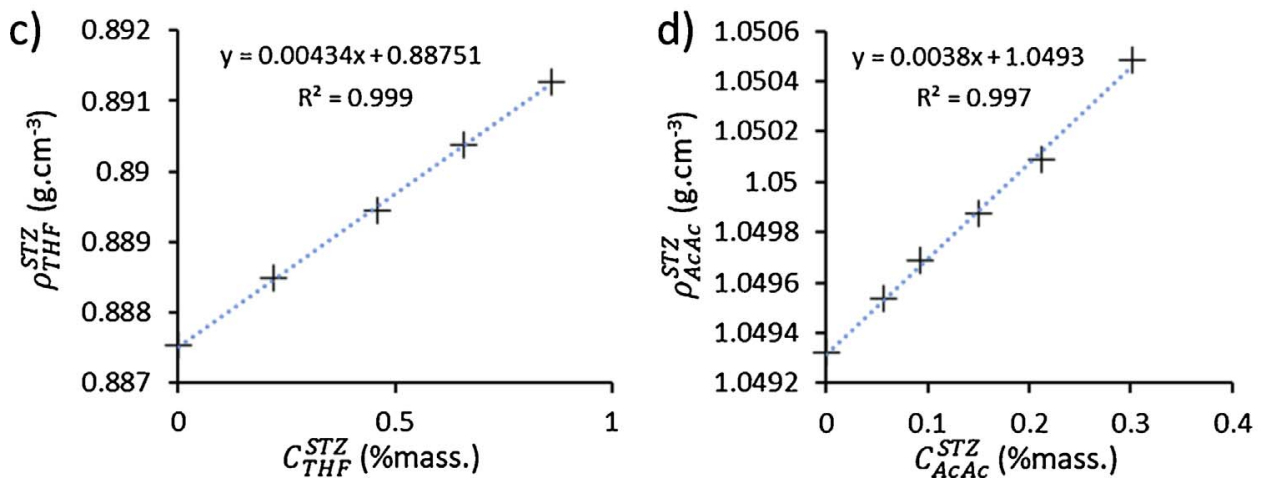

\subsection{Influence of operating conditions on polymorphic form}

The SAS experimental conditions performed during this work are listed in Table 3. Polymorphic form obtained from solid state NMR are also reported. ${ }^{13} \mathrm{C}$ NMR spectra are presented in Fig. 3, for powders of pure form I, pure form IV and a mixture of form I and IV.

For each of the three solvents, Acetone, Acetonitrile and Tetrahydrofuran, a dozen experiments mainly led to the formation of powders composed of a mixture of polymorphs (I and IV). Nevertheless, it is worth noting that for each solvent, pure polymorphic forms (I or IV) were obtained for given operating conditions. In addition, experiments with acetic acid led exclusively to the formation of pure polymorphic form I.

$\mathrm{CO}_{2}$ and organic solution (OS) flow rates as well as STZ concentration in the OS were varied to identify operating conditions allowing the formation of powders that exhibit only one polymorphic form. To interpret the effect of hydrodynamics on the polymorphic nature of obtained particles, Reynolds numbers describing the flows of the organic solution jet $\left(\mathrm{Re}_{\mathrm{jet}}\right)$ and of the carbon dioxide into the precipitation vessel $\left(\mathrm{Re}_{\mathrm{CO} 2}\right)$ were calculated as follows:

$R e_{j e t}=\frac{\rho_{\text {orga }} u_{\text {jet }} d_{\text {nozzle }}}{\mu_{\text {orga }}}$

$\operatorname{Re}_{\mathrm{CO}_{2}}=\frac{\rho_{\mathrm{CO}_{2}} u_{\mathrm{CO}_{2}} d_{\text {autoclave }}}{\mu_{\mathrm{CO}_{2}}}$

Where $\rho_{\text {orga }}$ and $\rho_{\mathrm{CO} 2}$ are measured organic solution and carbon dioxide densities, respectively, $\mathrm{u}_{\text {jet }}$ is the jet velocity at the exit of the injection nozzle of a diameter $d_{\text {nozzle }}$ of $127 \mu \mathrm{m}, \mathrm{u}_{\mathrm{CO} 2}$ is the $\mathrm{CO}_{2}$ velocity throughout the crystallization vessel (considering only $\mathrm{CO}_{2}$ ) of a diameter of $60 \mathrm{~mm}, \mu_{\text {orga }}$ (measured) and $\mu_{\mathrm{CO} 2}$ [36] are organic solution and carbon dioxide viscosities, respectively.

The Reynolds numbers associated to both flows correspond to laminar flows $(\operatorname{Re}<2500)$ since they vary from 73 to 2157 for the organic solution flow and from 15 to 155 for the $\mathrm{CO}_{2}$ flow. These values of Reynolds numbers correspond to different modes of jet dispersion; the highest values corresponding to atomized jet leading to more intense mixing conditions.

Furthermore, the characteristic times associated to the different effects controlling the jet dispersion were calculated [37]. Inertial, aerodynamic and viscous effects were calculated for each presented experiment. Inertial and aerodynamic effects are preponderant since their associated characteristic times, respectively between 16 up to $508 \mu$ s and 17 up to $599 \mu$ s, are the lowest in comparison with times associated with the viscous effects ( 20 up to $37 \mathrm{~ms}$ ). Inertial effects have a stabilizing effect on the jet during its dispersion while aerodynamic effects are destabilizing ones.

It is evidenced that intense mixing conditions, such as for experiments \#3, \#18, \#31 or \#41, lead to the formation of pure form I. In this case, mass transfers are enhanced, and so are the nucleation rates. Besides, less intense mixing conditions such as for experiments \#11, $\# 12$, \#22, \#23, \#34 or \#38, lead to the formation of form IV.

Acetic acid used as solvent represents an interesting case, as it only allows the formation of pure form I, whatever the operating conditions. It is also the only polar protic solvent used in this study. The presence of pure form I is observed at every operating condition, at both intense and moderate mixing conditions. Further investigations are required to fully interpret this observation. Experiments \#41, \#42 and \#43 are therefore not considered in the following interpretation.

For experiments that led to pure polymorphic form, the $\mathrm{Re}_{\mathrm{jet}}$ and $\mathrm{Re}_{\mathrm{CO} 2}$ are plotted in Fig. 4. Points obtained from acetic acid were removed.

It shows a clear influence of the $\mathrm{Re}_{\mathrm{jet}}$ on the obtained form. Amongst the presented experimental conditions, excluding points from acetic acid, every pure powder obtained at $\mathrm{Re}_{\text {jet }} \leq 508$ is pure form IV, while every pure powder obtained at $\mathrm{Re}_{\mathrm{jet}} \geq 1058$ is pure form I. A region where both pure form I and pure form IV were obtained is observed at $661 \leq \mathrm{Re}_{\text {jet }} \leq 726$. It can be noticed that the only pure form I present in this region was obtained with a higher STZ concentration in the OS ( $\beta_{\mathrm{OS}}=70 \%, 60 \%$ for the other ones). Furthermore, the $\mathrm{CO}_{2}$ flow rate has no direct influence on the obtained form. Indeed, both pure form I and IV were obtained at either higher or lower $\mathrm{Re}_{\mathrm{CO} 2}$ values. Therefore, the mixing is more dependent on the organic solution flow rate than on the $\mathrm{CO}_{2}$ flow rate. Obtaining a pure form IV hence has more chance to 


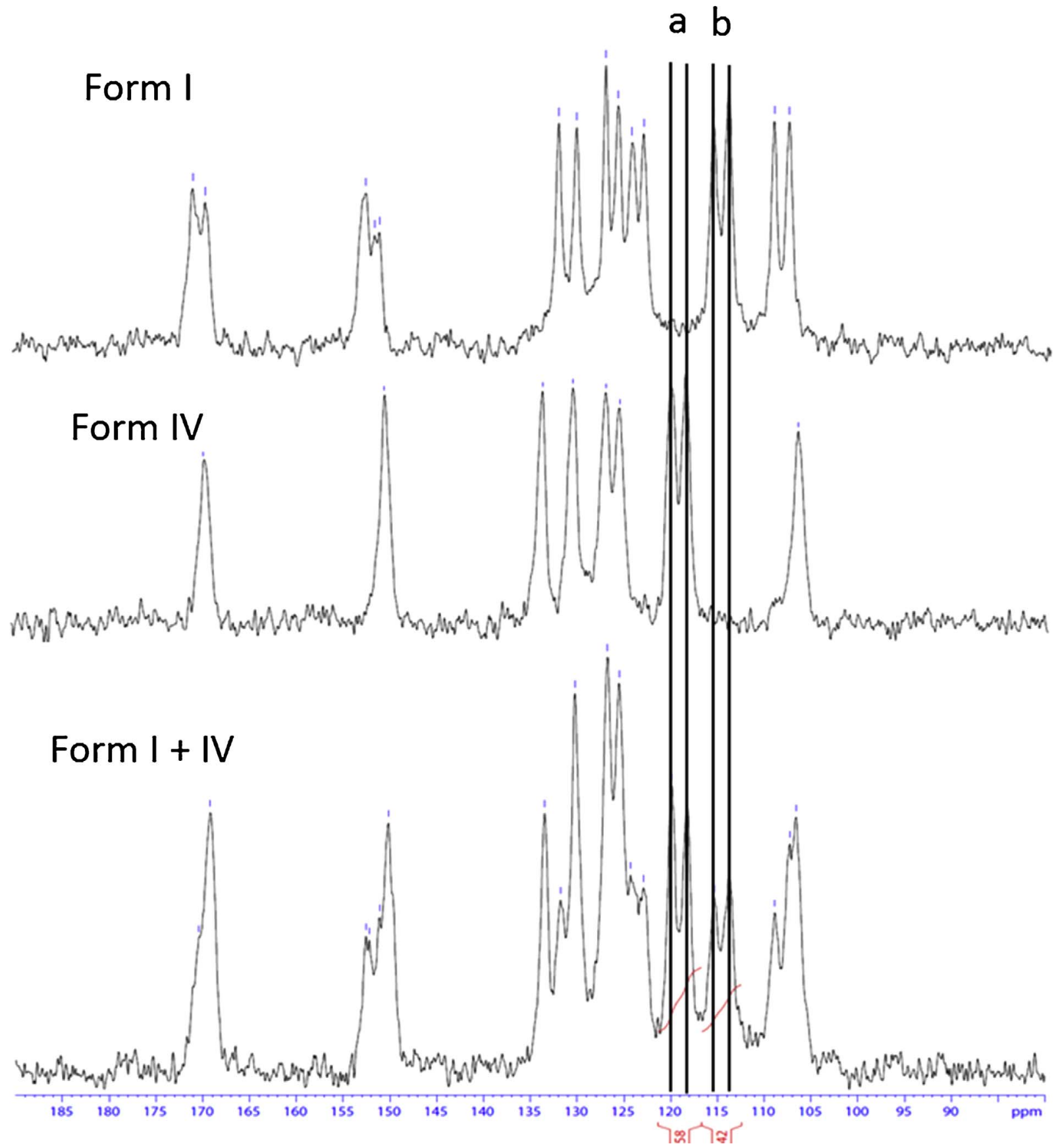

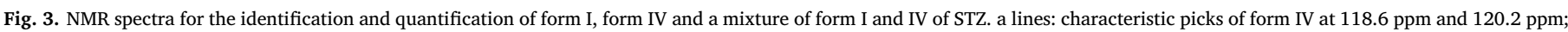
b lines: characteristic picks of form I at $114.2 \mathrm{ppm}$ and $115.7 \mathrm{ppm}$.

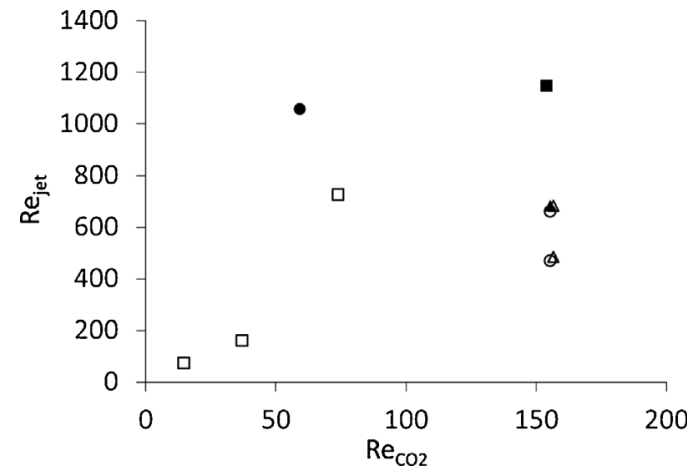

Fig. 4. $\mathrm{Re}_{\mathrm{jet}}$ and $\mathrm{Re}_{\mathrm{CO} 2}$ numbers of conditions that led to pure polymorphic form. Form I powders were obtained in acetone $(\boldsymbol{\square})$, acetonitrile $(\boldsymbol{\Lambda})$ and tetrahydrofuran $(\boldsymbol{\bullet})$; Form IV powders were obtained in acetone $(\square)$, acetonitrile $(\triangle)$ and tetrahydrofuran $(O)$.
Table 4

Repeatability measurement.

\begin{tabular}{ll}
\hline \# Exp. & Polymorphic form \\
\hline 4 & Mixture (I + IV) \\
$4^{\prime}$ & Mixture (I + IV) \\
$4^{\prime \prime}$ & Mixture (I + IV) \\
12 & IV \\
$12^{\prime}$ & IV \\
\hline
\end{tabular}

occur at lower $\mathrm{Re}_{\mathrm{jet}}$, independently of $\mathrm{Re}_{\mathrm{CO} 2}$.

The $\mathrm{X}_{\text {solv/CO2 }}$ values in which pure forms were obtained are ranged between $7.3 \%$ up to $20 \%$ for form I and $3.4 \%$ up to $11 \%$ for form IV. There is therefore no evidence that the polymorphic form of a pure 
powder is directly dependent on this variable. Indeed, $\mathrm{X}_{\mathrm{solv} / \mathrm{CO} 2}$ has a complex influence on the polymorphic form: as it rises, the solute solubility in the continuous fluid phase increases and, consequently, the overall supersaturation decreases and the concentration gradient between the dispersed and the continuous phases decreases. This slows down the nucleation and growth rate and thus may promote the formation of the most stable form. For example, Kordikowski et al. measured the STZ molar solubility in both pure and methanol modified $\mathrm{CO}_{2}$. At $10 \mathrm{MPa}$ and $313 \mathrm{~K}$, it rises from $8.1 \times 10^{-9}$ in pure $\mathrm{CO}_{2}$ to $1.56 \times 10^{-5}$ in the modified phase containing $\mathrm{X}_{\text {methanol } / \mathrm{CO} 2}=0.1412$ [19]. However, the highest values of $\mathrm{X}_{\text {solv/CO2 }}$ are inevitably obtained at high organic solution flow rates, which promotes the formation of the less stable form due to more intense mixing conditions.

Solvent nature also has an important influence over the polymorphic form for given flow rates of both phases. Indeed, some key comparisons, for example experiments \#4, \#19 and \#34 together, or experiments \#7, \#20 and \#35 together, show that for a different solvent but with similar flow rates of both phases, the resulting powder is different. Indeed, in the first mentioned set, an organic solution flow rate of $1.9 \mathrm{~mL} \mathrm{~min}^{-1}$ and a $\mathrm{CO}_{2}$ flow rate of $21 \mathrm{~g} \mathrm{~min}^{-1}$ are applied.
When acetone is used (\#4), a polymorphic mixture is obtained, whereas when acetonitrile (\#19) or tetrahydrofuran (\#34) are used, a pure form IV powder is obtained. In the second mentioned set, the organic solution flow rate was set at $1.9 \mathrm{~mL} \mathrm{~min}^{-1}$ and the $\mathrm{CO}_{2}$ flow rate was set at $10 \mathrm{~g} \mathrm{~min}^{-1}$. In this case, when the organic solvent is acetone (\#7), the obtained powder is $100 \%$ form IV, while a mixture of both was obtained when acetonitrile (\#20) or tetrahydrofuran (\#35) are used.

The initial concentration of STZ in the organic solution also has an influence on the polymorphic behavior as it has a direct connection with overall supersaturation. Experiments \#18 and \#19, using acetonitrile as solvent, show a shift in the polymorphic form of resulting powders from pure form IV to pure form I induced by an increased STZ concentration in the organic solution form $\beta=0.6$ to $\beta=0.7$. This induces a higher supersaturation, thus a faster nucleation and growth

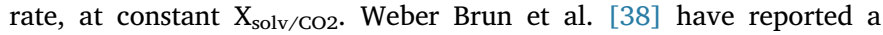
contradictory behavior in the case of caffeine crystallized with SAS. A higher proportion of the stable form (at ambient condition of pressure and temperature) has been observed at high initial concentration of solute. However, the proportion of crystalline material (crystalline versus amorphous) decreases by increasing initial concentration of
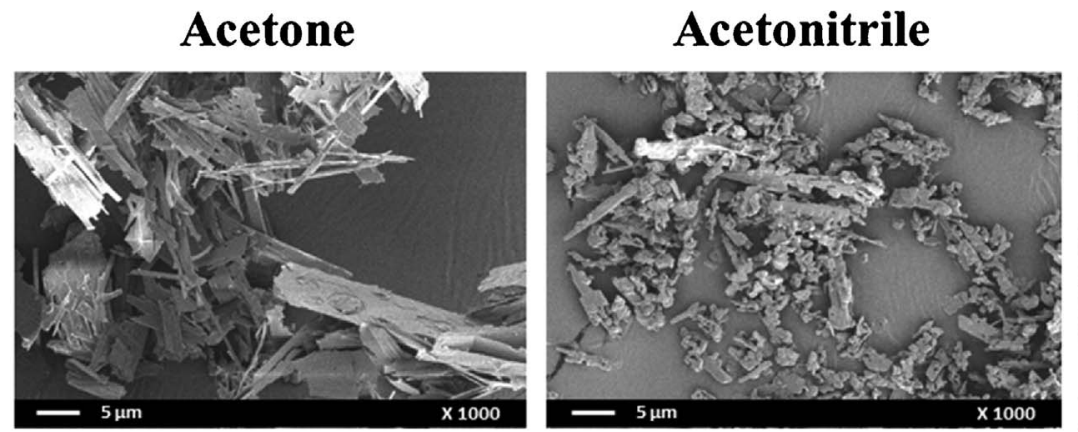

\section{Tetrahydrofuran}
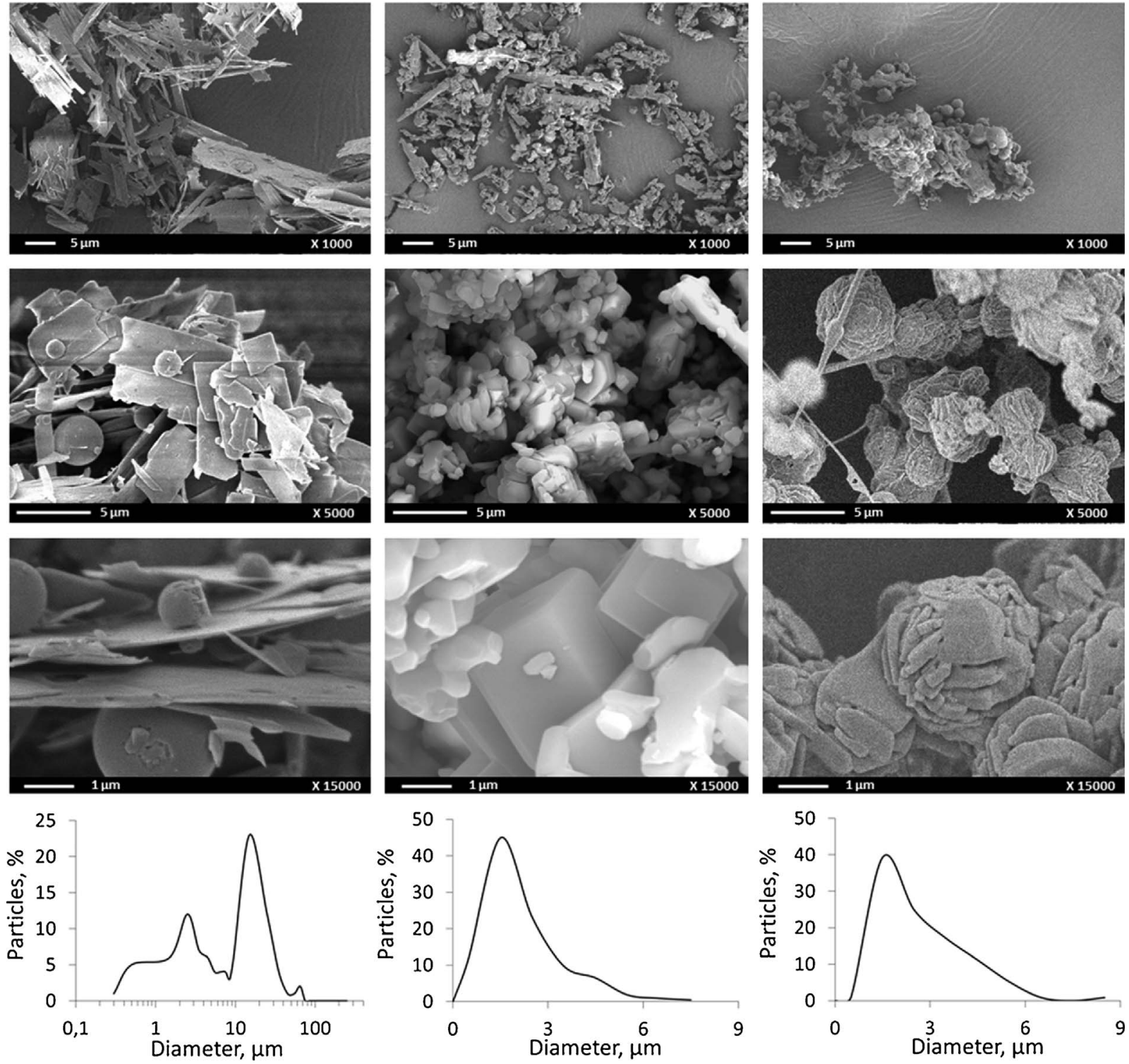

Fig. 5. SEM observations and PSD of form IV of sulfathiazole, obtained with exp. \#7 (acetone), exp. \#19 (acetonitrile) and exp. \#34 (tetrahydrofuran). 

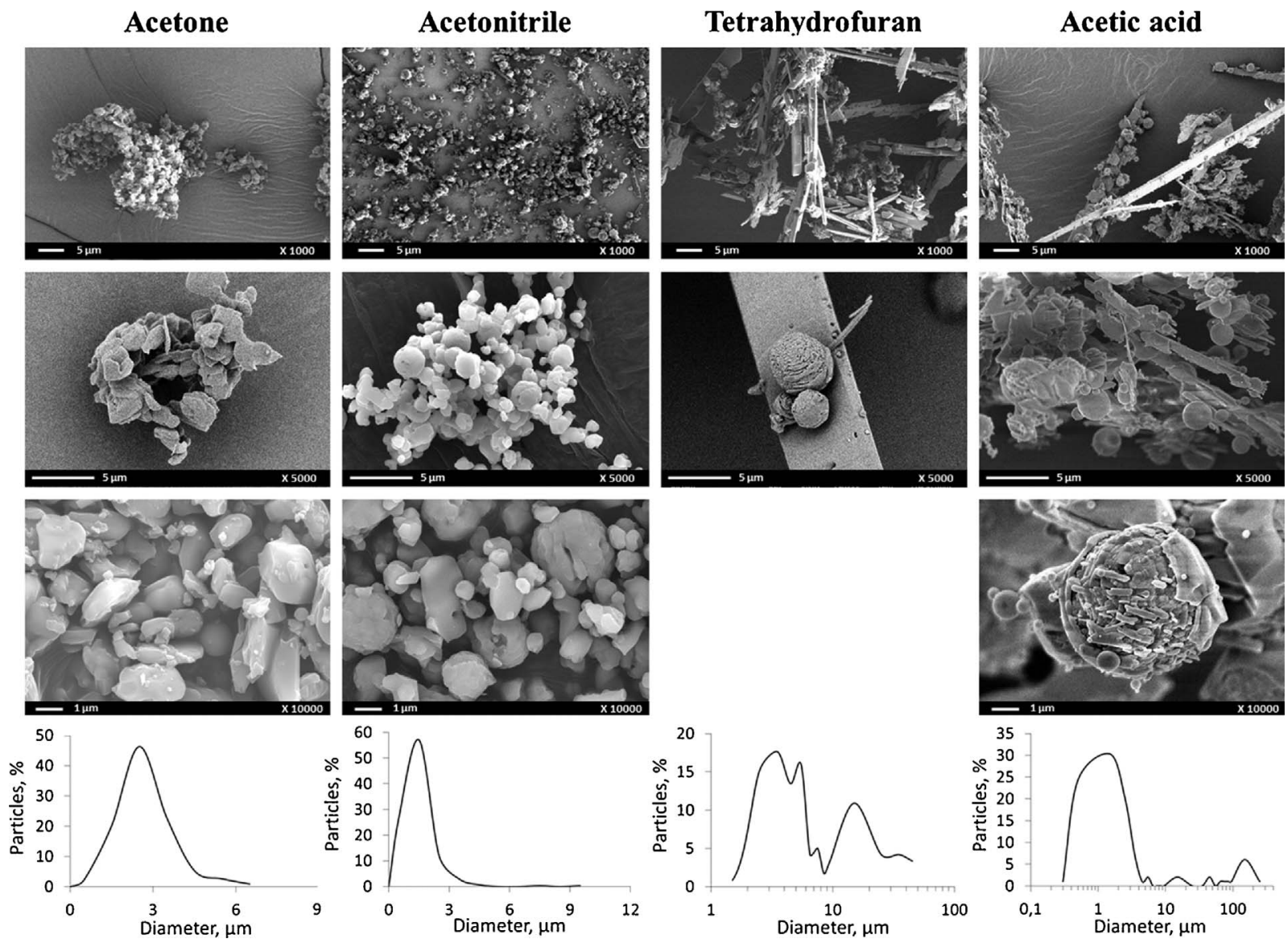

Fig. 6. SEM observations and PSD of form I of sulfathiazole, obtained with exp. \#3 (acetone), exp. \#18 (acetonitrile), exp. \#31 (tetrahydrofuran) and exp. \#41 (acetic acid).

solute. In the case of a solute exhibiting more than one polymorphic form, the obtained form is not only control by the initial concentration of solute but can depend on a variety of process parameters.

Repeatability was measured for some experiments. Two reproduced experiments are given in Table 4, namely \#4' and \#4" repeating experiments $\# 4$, and $\# 12$ ' repeating experiment $\# 12$. In every case, when either a mixture or a pure form is obtained, the repeatability is verified.

\subsection{SEM observations}

Crystalline powders from experiments \#3, \#7, \#18, \#19, \#31, \#34 and \#41 (Table 3), pure in one polymorphic form, were observed with SEM. Their habits are presented in SEM photographs for forms IV and I in Fig. 5 and Fig. 6, respectively.

A wide variation of crystals habit can be shown for the form IV of STZ (Fig. 5). When reprocessed by SAS from pure acetone (\#7), STZ crystals exhibit large and extremely thin plate- or leaf-like habit. The particle size distribution (PSD) shows two peaks, one around $3 \mu \mathrm{m}$ and the other around $20 \mu \mathrm{m}$. This distribution is classical in the case of fragile crystals. The smaller particles are the result of either attrition during the crystallization/washing steps, leading to the formation of spherical particles (diameter under or close to $1 \mu \mathrm{m}$ ), or mechanical breaking of larger crystals, inside the reactor, during the collecting step or during the SEM sample preparation. When acetonitrile was used as a solvent (\#19), crystal habit was equant. The obtained powder has a narrow PSD, at around $2 \mu \mathrm{m}$. Lastly, when the solvent used was tetrahydrofuran (\#34), crystal habit is of a plate-like type like that of acetone. An important aggregation is however evidenced with the formation of spherical clusters. This behavior prevents attrition and breaking from occurring, the obtained powder therefore has a narrow PSD.
From these pictures, two different crystallization mechanisms have been identified:

(a) A nucleation and growth mechanism, leading to particles with a crystal shape, such as those obtained in acetone (Fig. 5, \#7) and acetonitrile (Fig. 5, \#19). This highlights a gas-like phase composed of all the 3 components in a continuous, mixed phase. Crystal growth occurs by the successive adhesion of crystal units that diffuses through the bulk. In this liquid-like behavior, the growth rate strongly depends on the probability of a crystal unit meeting a grown crystal. Reducing the crystal size can therefore be achieved by decreasing the solute concentration, for example.

(b) A droplet drying mechanism, leading to quasi-spherical particles composed of aggregated nanocrystals, such as those obtained in tetrahydrofuran (Fig. 5, \#34). In this case, an interface still exists between the $\mathrm{CO}_{2}$-rich phase and the organic solution droplet, imposing the spherical shape of generated particles. Crystallization kinetics are therefore highly dependent on the double-diffusivity effect, mostly affected by the affinity between solvent and $\mathrm{CO}_{2}$.

STZ crystals of form I (Fig. 6) exhibit two different crystal habits, namely needle-like, and aggregated clusters of plate-like habits, corresponding to the nucleation and growth mechanism and the droplet drying mechanism, respectively. The latter is observable with all tested solvent, while being mainly observed with acetone and acetonitrile (\#3 and $\# 18$, respectively, $100 \%$ of observed particles), but also visible with tetrahydrofuran (\#31) and with acetic acid (\#41). The nucleation and growth mechanism is only observable when tetrahydrofuran and acetic acid were used, both experimental conditions leading to needlelike crystals. This habit clearly indicates that the growth rate of one or a couple of faces has been slowed down. PSD for an observed sample with 
both acetone and acetonitrile are narrow around 3 and $2 \mu \mathrm{m}$, respectively. However, with both tetrahydrofuran and acetic acid, the PSD is widely distributed. This is due to the combined presence of needle-like crystals and spherical clusters. The smaller particles are observed in the case of acetic acid used as a solvent.

This large habit disparity of crystal habits, for both polymorphic forms IV and I, highlights how important the solvent is for controlling crystal habit. The solvent acts as a growth inhibitor for a given set of crystal faces by adsorbing differently at the surface of every crystal face. The higher the solvent adsorption, the higher the drop of the surface free energy, for a given crystal face. Moreover, it is well established that the different surface free energy of each crystal's face is habit-controlling, and can be modified by solvent adsorption [39]. Therefore, predicting the crystal habit can be performed by predicting the surface energy as well as solvent adsorption energies thanks to molecular modelling [40]. A current work consisting in the prediction of solvent adsorption energies for STZ is ongoing to validate the method for crystallization in a supercritical medium.

\section{Conclusions}

The polymorphic and habit control of sulfathiazole has been studied from the supercritical antisolvent process and with different organic solvents. At moderate mixing conditions and for low supersaturation values, the form IV is obtained, whilst at intense mixing conditions, fast nucleation kinetics lead to formation of form I. Furthermore, crystal habit can be severely influenced by the solvent. Indeed, depending on the solvent nature, polymorphic form IV crystals of sulfathiazole can exhibit a thin plate-like habit or an equant habit. The same behavior occurs for the polymorphic form I crystals of sulfathiazole, exhibiting either a plate-like habit or a needle-like habit. More importantly, two crystallization mechanisms have been identified and are affected by the nature of solvent. These two mechanisms are liquid-like nucleation and growth mechanism and droplet drying mechanism, and depend on hydrodynamic conditions as well as on the affinity between organic solvent and $\mathrm{CO}_{2}$. These two behaviors further point out how important and complex the choice of a solvent is for particle generation with the supercritical anti-solvent process.

The strong dependence of crystal habit on the solvent used, in the case of nucleation and growth mechanism, can be imputed to the solvent's ability (or inability) to perform strong intermolecular interactions with a given set of crystal faces. These intermolecular interactions can be regarded as solvent molecules adsorbed at the surface of a crystal, which may be the cause of the crystal habit changes. Adsorption energies can be calculated through molecular modelling to predict and control the crystal habit, for example in a drug producing perspective.

\section{Acknowledgments}

The authors gratefully thank Fabio ZIARELLI for characterization by RMN spectrometry and helpful discussions.

\section{References}

[1] S.-D. Yeo, M.-S. Kim, J.-C. Lee, Recrystallization of sulfathiazole and chlorpropamide using the supercritical fluid antisolvent process, J. Supercrit. Fluids 25 (2003) 143-154, http://dx.doi.org/10.1016/S0896-8446(02)00094-3.

[2] J. Fages, H. Lochard, J.-J. Letourneau, M. Sauceau, E. Rodier, Particle generation for pharmaceutical applications using supercritical fluid technology, Powder Technol. 141 (2004) 219-226, http://dx.doi.org/10.1016/j.powtec.2004.02.007.

[3] Y.-M. Chen, M. Tang, Y.-P. Chen, Recrystallization and micronization of sulfathiazole by applying the supercritical antisolvent technology, Chem. Eng. J. 165 (2010) 358-364, http://dx.doi.org/10.1016/j.cej.2010.08.075.

[4] M.A. Rodrigues, L. Padrela, V. Geraldes, J. Santos, H.A. Matos, E.G. Azevedo, Theophylline polymorphs by atomization of supercritical antisolvent induced suspensions, J. Supercrit. Fluids 58 (2011) 303-312, http://dx.doi.org/10.1016/j. supflu.2011.05.012.

[5] E. Badens, Mise en forme de principes actifs pharmaceutiques en phase supercritique, Tech. Ing. Génie Procédés. (2012) Ref: chv4010.
[6] M.T. Fernández-Ponce, Y. Masmoudi, R. Djerafi, L. Casas, C. Mantell, E.M. de la Ossa, E. Badens, Particle design applied to quercetin using supercritical anti-solvent techniques, J. Supercrit. Fluids. 105 (2015) 119-127, http://dx.doi.org/10.1016/j. supflu.2015.04.014.

[7] R. Djerafi, Y. Masmoudi, C. Crampon, A. Meniai, E. Badens, Supercritical anti-solvent precipitation of ethyl cellulose, J. Supercrit. Fluids. 105 (2015) 92-98, http:// dx.doi.org/10.1016/j.supflu.2015.02.033.

[8] M.C. Guamán-Balcázar, A. Montes, C. Pereyra, E.M. de la Ossa, Precipitation of mango leaves antioxidants by supercritical antisolvent process, J. Supercrit. Fluids 128 (2017) 218-226, http://dx.doi.org/10.1016/j.supflu.2017.05.031.

[9] I. García-Casas, A. Montes, C. Pereyra, E.J. Martínez de la Ossa, Generation of quercetin/cellulose acetate phthalate systems for delivery by supercritical antisolvent process, Eur. J. Pharm. Sci. 100 (2017) 79-86, http://dx.doi.org/10.1016/j. ejps.2017.01.010.

[10] D.S. Hughes, M.B. Hursthouse, T. Threlfall, S. Tavener, A new polymorph of sulfathiazole, Acta Crystallogr. Sect. C. 55 (1999) 1831-1833, http://dx.doi.org/10. 1107/S0108270199010112.

[11] G.J. Kruger, G. Gafner, The crystal structures of polymorphs I and III of sulphathiazole, Acta Crystallogr. B. 28 (1972) 272-283, http://dx.doi.org/10.1107/ S0567740872002183.

[12] N. Blagden, R.J. Davey, H.F. Lieberman, L. Williams, R. Payne, R. Roberts, R. Rowe, R. Docherty, Crystal chemistry and solvent effects in polymorphic systems Sulfathiazole, J. Chem. Soc. Faraday Trans. 94 (1998) 1035-1044, http://dx.doi. org/10.1039/A706669D.

[13] D.C. Apperley, R.A. Fletton, R.K. Harris, R.W. Lancaster, S. Tavener, T.L. Threlfall, Sulfathiazole polymorphism studied by magic-angle spinning NMR, J. Pharm. Sci. 88 (1999) 1275-1280, http://dx.doi.org/10.1021/js990175a.

[14] N. Blagden, Crystal engineering of polymorph appearance: the case of sulphathiazole, Powder Technol. 121 (2001) 46-52, http://dx.doi.org/10.1016/S00325910(01)00373-4.

[15] I. Sovago, M.J. Gutmann, J.G. Hill, H.M. Senn, L.H. Thomas, C.C. Wilson, L.J. Farrugia, Experimental electron density and neutron diffraction studies on the polymorphs of sulfathiazole, Cryst. Growth Des. 14 (2014) 1227-1239, http://dx. doi.org/10.1021/cg401757z.

[16] M.R. Abu Bakar, Z.K. Nagy, C.D. Rielly, S.E. Dann, Investigation of the riddle of sulfathiazole polymorphism, Int. J. Pharm. 414 (2011) 86-103, http://dx.doi.org/ 10.1016/j.ijpharm.2011.05.004.

[17] C.-S. Su, P.-Y. Wu, W.-D. Jheng, Recrystallization of phenacetin and sulfathiazole using the sonocrystallization process, J. Taiwan Inst. Chem. Eng. 59 (2016) 106-112, http://dx.doi.org/10.1016/j.jtice.2015.08.009.

[18] M. Kitamura, M. Yamamoto, Y. Yoshinaga, H. Masuoka, Crystal size control of sulfathiazole using high pressure carbon dioxide, J. Cryst. Growth 178 (1997) 378-386, http://dx.doi.org/10.1016/S0022-0248(96)01190-6.

[19] A. Kordikowski, M. Siddiqi, S. Palakodaty, Phase equilibria for the $\mathrm{CO} 2+$ methanol + sulfathiazole system at high pressure, Fluid Phase Equilib. 194-197 (2002) 905-917, http://dx.doi.org/10.1016/S0378-3812(01)00649-5.

[20] V.C. Stefano Bianco, Modification of the solid-state nature of sulfathiazole and sulfathiazole sodium by spray drying, AAPS PharmSciTech 13 (2012) 647-660, http://dx.doi.org/10.1208/s12249-012-9792-5.

[21] Á. Munroe, Å.C. Rasmuson, B.K. Hodnett, D.M. Croker, Relative stabilities of the five polymorphs of sulfathiazole, Cryst. Growth Des. 12 (2012) 2825-2835, http:// dx.doi.org/10.1021/cg201641Ág.

[22] E. Reverchon, R. Adami, G. Caputo, I. De Marco, Spherical microparticles production by supercritical antisolvent precipitation: interpretation of results, J. Supercrit. Fluids 47 (2008) 70-84, http://dx.doi.org/10.1016/j.supflu.2008.06.002.

[23] A. Erriguible, T. Fadli, P. Subra-Paternault, A complete 3D simulation of a crystallization process induced by supercritical $\mathrm{CO} 2$ to predict particle size, Comput Chem. Eng. 52 (2013) 1-9, http://dx.doi.org/10.1016/j.compchemeng.2012.12. 002.

[24] T. Petit-Gas, O. Boutin, I. Raspo, E. Badens, Role of hydrodynamics in supercritical antisolvent processes, J. Supercrit. Fluids 51 (2009) 248-255, http://dx.doi.org/10 1016/j.supflu.2009.07.013.

[25] S. Careno, O. Boutin, E. Badens, Drug recrystallization using supercritical antisolvent (SAS) process with impinging jets: effect of process parameters, J. Cryst. Growth. 342 (2012) 34-41, http://dx.doi.org/10.1016/j.jcrysgro.2011.06.059.

[26] O. Boutin, C. Maruejouls, G. Charbit, A new system for particle formation using the principle of the SAS process: the Concentric Tube Antisolvent Reactor (CTAR), J. Supercrit. Fluids 40 (2007) 443-451, http://dx.doi.org/10.1016/j.supflu.2006.07. 012.

[27] P. Chattopadhyay, R.B. Gupta, Production of griseofulvin nanoparticles using supercritical CO2 antisolvent with enhanced mass transfer, Int. J. Pharm. 228 (2001) 19-31, http://dx.doi.org/10.1016/S0378-5173(01)00803-1.

[28] B. De Gioannis, P. Jestin, P. Subra, Morphology and growth control of griseofulvin recrystallized by compressed carbon dioxide as antisolvent, J. Cryst. Growth. 262 (2004) 519-526, http://dx.doi.org/10.1016/j.jcrysgro.2003.10.025.

[29] E. Reverchon, Supercritical antisolvent precipitation of micro- and nano-particles, J. Supercrit. Fluids. 15 (1999) 1-21, http://dx.doi.org/10.1016/S0896-8446(98) 00129-6.

[30] B.-M. Lee, J.-S. Jeong, Y.-H. Lee, B.-C. Lee, H.-S. Kim, H. Kim, Y.-W. Lee, Supercritical antisolvent micronization of cyclotrimethylenetrinitramin: influence of the organic solvent, Ind. Eng. Chem. Res. 48 (2009) 11162-11167, http://dx.doi. org/10.1021/ie900448w.

[31] G. Caputo, R. Adami, E. Reverchon, Supercritical fluid crystallization of adipic acid using urea as habit modifier, Cryst. Growth Des. 8 (2008) 2707-2715, http://dx doi.org/10.1021/cg700753u.

[32] A. Kordikowski, T. Shekunov, P. York, Polymorph control of sulfathiazole in 
supercritical CO2, Pharm. Res. 18 (2001) 682-688, http://dx.doi.org/10.1023/ A:1011045729706.

[33] A. Bouchard, N. Jovanović, G.W. Hofland, D.J.A. Crommelin, W. Jiskoot, G.J. Witkamp, Ways of manipulating the polymorphism of glycine during supercritical fluid crystallisation, J. Supercrit. Fluids 44 (2008) 422-432, http://dx.doi. org/10.1016/j.supflu.2007.09.016.

[34] M. Rossmann, A. Braeuer, A. Leipertz, E. Schluecker, Manipulating the size, the morphology and the polymorphism of acetaminophen using supercritical antisolvent (SAS) precipitation, J.Supercrit. Fluids 82 (2013) 230-237, http://dx.doi. org/10.1016/j.supflu.2013.07.015.

[35] D.R. Lide (Ed.), CRC Handbook of Chemistry and Physics, CRC Press, Boca Raton, FL, 2005.

[36] A. Fenghour, W.A. Wakeham, V. Vesovic, The viscosity of carbon dioxide, J. Phys. Chem. Ref. Data. 27 (1998) 31-44, http://dx.doi.org/10.1063/1.556013.
[37] E. Carretier, E. Badens, P. Guichardon, O. Boutin, G. Charbit, Hydrodynamics of supercritical antisolvent precipitation: characterization and influence on particle morphology, Ind. Eng. Chem. Res. 42 (2003) 331-338, http://dx.doi.org/10.1021/ ie020439v.

[38] G. Weber Brun, Á. Martín, E. Cassel, R.M.F. Vargas, M.J. Cocero, Crystallization of caffeine by supercritical antisolvent (SAS) process: analysis of process parameters and control of polymorphism, Cryst. Growth Des. 12 (2012) 1943-1951, http://dx. doi.org/10.1021/cg2016758.

[39] M. Saska, A.S. Myerson, The theoretical shape of sucrose crystals from energy calculations, J. Cryst. Growth 61 (1983) 546-555, http://dx.doi.org/10.1016/ 0022-0248(83)90183-5.

[40] C.H. Lin, N. Gabas, J.P. Canselier, G. Pèpe, Prediction of the growth morphology of aminoacid crystals in solution: i. $\alpha$-Glycine, J. Cryst. Growth 191 (1998) 791-802, http://dx.doi.org/10.1016/S0022-0248(98)00130-4. 